Note

\title{
UV-Blocking Film for Food Storage using Titanium Dioxide
}

\author{
Akihiko НАSнімото* and Koji SАKАмото \\ Hiroshima Prefectural Technology Research Institute, Food Technology Research Center, 12-70, Hijiyamahon-machi, Minami-ku, Hiroshima \\ 732-0816, Japan
}

Received July 8, 2010; Accepted February 8, 2011

We aimed to develop UV-blocking clear films for foods using the harmless titanium dioxide. The blocking rate for short-wavelength UV light $(200 \mathrm{~nm}-300 \mathrm{~nm})$ was $99.2 \%$, while that for long-wavelength UV light $(300 \mathrm{~nm}-400 \mathrm{~nm})$ was $70.9 \%$. The coating was transparent and adhered strongly to the films according to the JIS rule.

Keywords: UV-blocking, food, titanium dioxide, coating, UV-induced deterioration

\section{Introduction}

In recent years, the irradiation exposure of foods to fluorescent light has shown an increasing tendency due to the extension of working hours in supermarkets and convenience stores. However, it is difficult to control food deterioration caused by UV light using conventional techniques (Cladman et al., 1998; Vassila et al., 2002; White, 1985). Common light-blocking films such as aluminized films maybe undesirable as packaging materials because they hide the food contents from customers. It is also possible that the migration of certain organic UV absorbers contained in UV-blocking films affects food safety (Pascall et al., 1995). For these reasons, the development of a safe and transparent UV-blocking film is currently required in the food industry (Fanelli et al., 1985; Irissin-Mangata et al., 2000; Schroder et al., 1985; Van Aardt et al., 2001).

On the other hand, many organic or inorganic lightblocking materials for UV-blocking coatings have been developed for reconfiguring the substrate film surface (Fanta et al., 2002; Fayet et al., 1995; Hartwig, 1994; Hoffmann et al., 1994; Kelly, 1994; Lippens et al., 1998; Lohwasser et al., 1995; Schiller et al., 1996; Schiller et al., 1998; Schiller et al., 1999; Watanabe et al., 1997). Titanium dioxide has been used as a photocatalyst and UV-blocking agent and, according to the food sanitation law, is allowed as a food additive (e.g., white pigment). Titanium dioxide is also used in fields other than the food industry, for example as a colorant and

*To whom correspondence should be addressed. E-mail: a-hashimoto86253@pref.hiroshima.lg.jp
UV-blocking agent in paint and cosmetics. Titanium alkoxide is a well-known raw material used in the preparation of titanium dioxide coatings on glass or metal surfaces. Titanium dioxide is generated by heating titanium alkoxide through the sol-gel process. Therefore, it is difficult to coat plastic film with titanium dioxide.

Ichinose et al. (2001a; 2001b) reported on the preparation method of peroxotitanium acid solution by the addition of hydrogen peroxide solution to peroxotitanium dinuclear complex anions $\left(\mathrm{Ti}_{2} \mathrm{O}_{5}(\mathrm{OH})_{\mathrm{x}}^{(\mathrm{x}-2)-}, \mathrm{x}>2\right)$. Peroxo-modified anatase sol was produced by the heating of peroxotitanium acid solution. The peroxo-modified anatase sol contained dispersed anatase crystallites $(<30 \mathrm{~nm})$ in spite of its neutral $\mathrm{pH}$. The sol is useful for coating plastic films because anatase titanium dioxide generates fine particles at room temperature. Photocatalytic activity appears on the plastic film surface by simply coating the plastic film with the sol.

In the present study, we developed a safe UV-blocking coating film using peroxo-modified anatase sol.

\section{Materials and Methods}

The test film used in coating was of oriented polypropylene (OPP). The film thickness was $40 \mu \mathrm{m}$. One side of the film was factory surface modified by corona-treatment.

The coating liquid was composed of peroxo-modified anatase sol (PA sol, 0.7 wt\%, Ohno Oil, Hiroshima, Japan), methyl cellulose (MC, $1500 \mathrm{cP}, 1 \mathrm{wt} \%$ solution, Wako, Osaka, Japan) and methyl methacrylate (MM, 10 vol\% ethanol solution, Wako).

The films (width $300 \mathrm{~mm}$, length $450 \mathrm{~mm}$ ) were fixed 
on an IMC-7000 control coater (Imoto, Kyoto, Japan) and coated on the corona-treated side by means of a micrometer adjustment-type frame applicator (which allows for adjustment of the wet-film thickness). After coating, the films were dried at room temperature. In the case of multiple coatings, the coated films were fixed on the control coater and were recoated after drying.

The UV-visible transmittance spectra of the coatings were measured by means of a UV-1600 spectrophotometer (Shimadzu, Kyoto, Japan).

The adhesion of the coating was analyzed via a JIS K5600-5-6 adhesion test (International Organization for Standardization, 2007; Japanese Industrial Standards Committee, 1999). The coated films were cross-cut at a width of $1 \mathrm{~mm}$. Cellulose tape (Nichiban, Tokyo, Japan) or packaging tape was stuck on the coated films, and the remnants of the coating after unsticking were checked and classified by the JIS rule. The adhesive force of the cellulose tape was 4.00 $\mathrm{N} / 10 \mathrm{~mm}$ (Japanese Industrial Standards Committee, 2009), and that of the packaging tape was $6.79 \mathrm{~N} / 10 \mathrm{~mm}$. According to the JIS rule, class 0 means no remnant after unsticking and class 5 means that almost all the coating is unstuck from the film.

\section{Results and Discussion}

Materials for coating were selected taking into consideration the safety of their use in or near foods. Polymethyl methacrylate (Ichimura and Kato, 2000) is an allowable food-packaging material according to the food sanitation law of Japan. Titanium dioxide is a photo-polymerization initiator of methyl methacrylate. However, it is difficult to coat

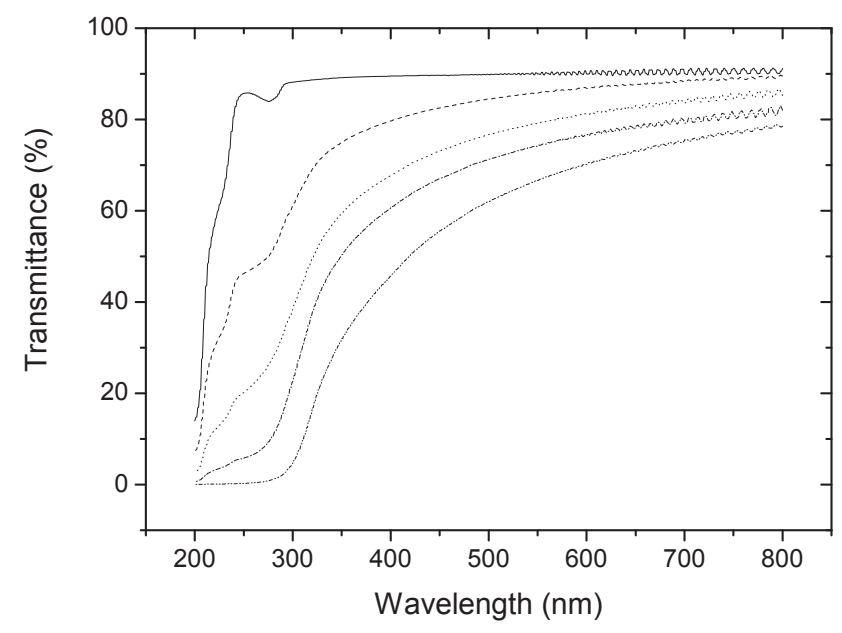

Fig. 1. UV-visible spectrum dependence on the number of coats. base film (OPP); ------- coating thickness of $100 \mu \mathrm{m}$ and one coat; ............ $100 \mu \mathrm{m}$ and three coats; -.-.-. $100 \mu \mathrm{m}$ and five coats; -..--.- $500 \mu \mathrm{m}$ and three coats. aqueous PA sol onto the surface of plastic film due to the hydrophobic surface of such film. Therefore, methyl cellulose was incorporated as a food thickener into the coating liquid to reinforce its wetability.

The mixture ratio of the coating liquid was PA sol:MC ( $1 \%$ aqueous solution):MM (10\% ethanol solution $)=7: 1: 2$. Figure 1 shows the dependence of the UV-visible spectrum on the number of coatings onto OPP film. As the number of coatings increased, the UV absorption (200 nm-300 nm) increased. The coating thickness of the frame applicator was set at $100 \mu \mathrm{m}$ or $500 \mu \mathrm{m}$, and the number of coatings was changed. The results showed that the short-wavelength UV light (200 nm - $300 \mathrm{~nm}$ ) was completely blocked, while the blocking rate for the long-wavelength UV light (300 nm-400 $\mathrm{nm}$ ) was $70.9 \%$. The absorption wavelength depended on the band gap of metallic oxides; therefore, it was difficult to increase the UV-blocking rate using only titanium dioxide. It is known that some foods are deteriorated by long-wavelength UV light (Chen et al., 1998). The band-gap for anatase type titanium dioxide is $3.2 \mathrm{eV}$ (Banerjee et al., 2006). Titanium dioxide absorbs ultraviolet light below $387 \mathrm{~nm}$.

The quantity of the titanium dioxide coating was varied by changing the coating conditions. Figure 2 shows the dependence of absorbance $(300 \mathrm{~nm})$ on the coating thickness of the frame applicator and the number of coatings. The blocking rate was $84.7 \%$ and absorbance was 0.792 at a coating thickness of $100 \mu \mathrm{m}$ and six coatings. The rate increased to $95.3 \%$ and the absorbance was 1.25 with a coating thickness of $500 \mu \mathrm{m}$ and three coatings. The number of coatings was proportional to the absorbance. According to regression analysis, the relationship between absorbance and number of

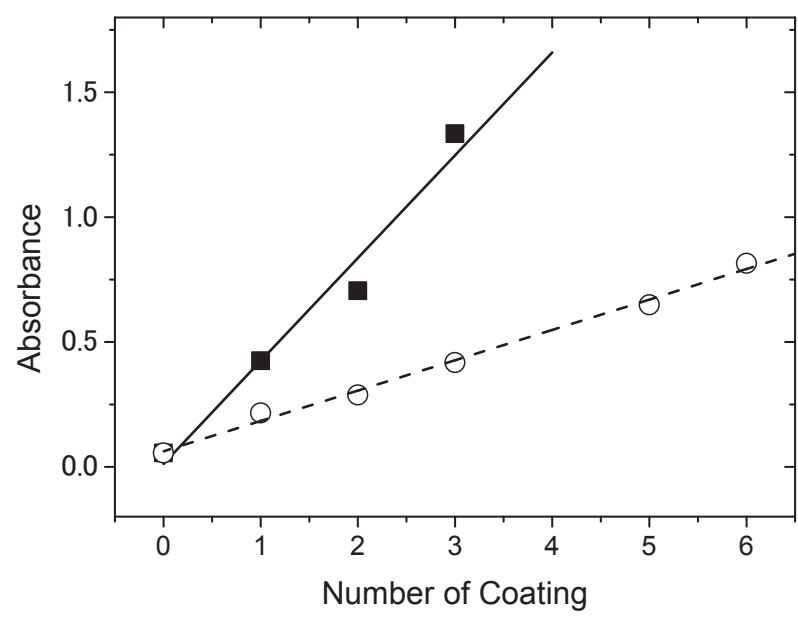

Fig. 2. Absorbance $(300 \mathrm{~nm})$ on the coating thickness of the frame applicator and the number of coats. $\odot$, coating thickness of $100 \mu \mathrm{m}$; -, $500 \mu \mathrm{m}$; line, linear regression analysis results. 


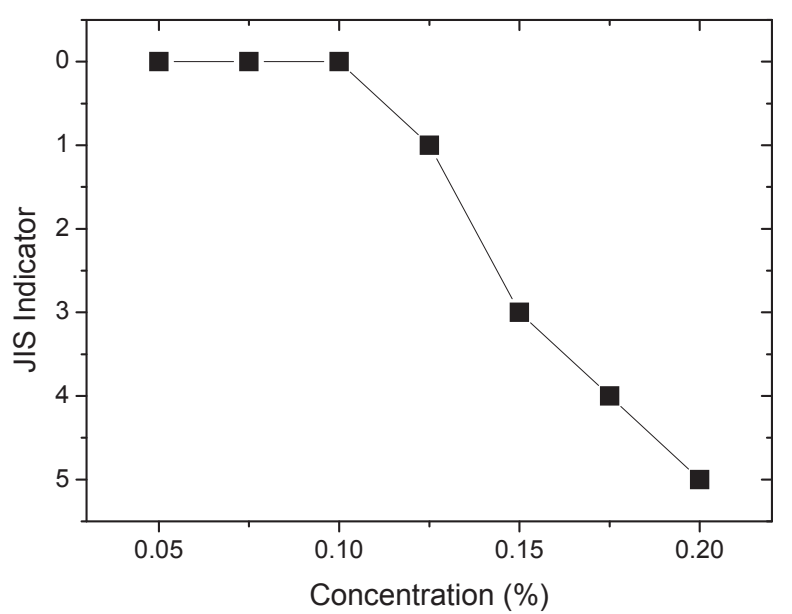

Fig. 3. Dependence of the coating adhesion on the MC concentration.

coatings is as follows:

$$
\begin{aligned}
& A_{500}=0.412 N_{500}+0.011 \\
& A_{100}=0.122 N_{100}+0.061
\end{aligned}
$$

( $A_{500}$; absorbance with a coating thickness of $500 \mu \mathrm{m}, A_{100}$; absorbance with a coating thickness of $100 \mu \mathrm{m}, N_{500}$; number of coatings with a coating thickness of $500 \mu \mathrm{m}, N_{100}$; number of coatings with a coating thickness of $100 \mu \mathrm{m}$ )

The application of one coating was most advantageous for lowering the production cost; however, in this study the best results were obtained when the coating thickness of the frame applicator was $500 \mu \mathrm{m}$ and the number of coatings was three.

The effect of the composition of the coating liquid was investigated. First, the dependence of coating adhesion on MC concentration was examined. The PA sol:MC:MM (10\% ethanol solution) ratio was $8: 1: 1$. The concentration of MM in the final mixture was $1 \%$. The concentrations of MC solutions were from $0.5 \%$ to $2 \%$ before mixing. The concentrations in the final mixture changed from $0.05 \%$ to $0.2 \%$. Figure 3 shows the dependence of coating adhesion on MC concentration onto OPP film. The adhesion strength was high when the concentration was below $0.1 \%$, but diminished above $0.1 \%$ and was very small at $0.2 \%$. It has been reported that titanium dioxide initiated the polymerization of methyl methacrylate by photocatalysis (Ozaki et al., 2001). MC seemed to be a reaction inhibitor of this polymerization process. It was possible that an increase of MC inhibited the curing of MM, resulting in a decrease in the adhesion strength of the coating.

The dependence of coating adhesion on MM concentration was also examined. The PA sol:MC (1\% aqueous solution):MM ratio was 8:1:1. The concentrations of MM

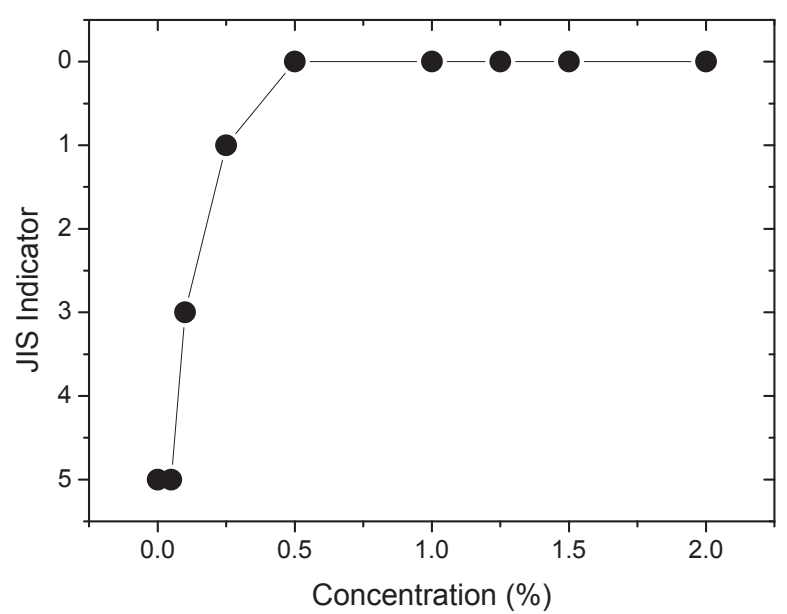

Fig. 4. Dependence of the coating adhesion on the MM concentration.

solutions were from $0 \%$ to $20 \%$ before mixing. The concentrations in the final mixture changed from $0 \%$ to $2 \%$, and the concentration of MC was fixed at $0.1 \%$. Figure 4 shows the dependence of coating adhesion on MM concentration onto OPP film. The adhesion strength was sufficient for practical use at MM concentrations above $0.5 \%$. However, the adhesion strength fell at MM concentrations below $0.5 \%$ and was very low at $0 \%$.

\section{Conclusion}

Oil in foods is greatly deteriorated by short-wavelength light (UV light, etc.) (Ohta, 1977; Pascall et al., 1995). The blocking of light with a wavelength of $350 \mathrm{~nm}$ or below can effectively prevent oil deterioration. Therefore, the application of this coating on food-packaging films is expected to protect oily foods and many other types of food from deterioration. Examination of the effect of this coating on the food deterioration process is required. This coating also has antibacterial properties, which are induced by the titanium dioxide photocatalysis (Matsuoka and Anpo, 2006; Togeda, 2006). We have already studied the photocatalysis of the coating and its relationship to the wetability change of the plastic substrate surface. The next step is to examine the antibacterial and antifungal activities of the coating.

A coating liquid with UV-blocking properties was prepared by mixing PA sol, MC and MM. The coating blocked $99.2 \%$ of the short-wavelength UV light $(200-300 \mathrm{~nm})$ and $70.9 \%$ of the long-wavelength UV light $(300-400 \mathrm{~nm})$. The titanium dioxide coating had a UV-blocking effect and was transparent, making it an ideal material for protecting foods against UV-induced deterioration.

\section{References}


Banerjee, S., Gopal, J., Muraleedharan, P., Tyagi, A. K., and Raj, B., (2006) Physics and chemistry of photocatalytic titanium dioxide: Visualization of bactericidal activity using atomic force microscopy. Current Sci., 90, 1378-1383.

Chen, B.H. et al., (1998) Degradation and isomerization of chlorophyll a and $\beta$-carotene as affected by various heating and illumination treatments. Food Chem., 62, 299.

Cladman, W., Scheffer, S., Goodrich, N., and Griffiths, M.W., (1998) Shelf-life of milk packaged in plastic containers with and without treatment to reduce light transmission. Int. Dairy J., 8, 629-636.

Fanelli, A.J., Burlew, J.V., and Gabriel, M.K., (1985) Protection of milk packaged in high density polyethylene against photodegradation by fluorescent light. J. Food Protection, 48, 112-117.

Fanta, G.F., Felker, F.C., Shogren, R.L., and Salch, J.H., (2002) Formation of hydrophilic starch coatings on polyethylene films. $J$. Appl. Polymer Sci., 84, 1781-1788.

Fayet, P. et al., (1995) "Commercialisation of plasma deposited barrier coatings for liquid food packaging." Society of Vacuum Coaters, 38th Ann. Tech. Conf. Proc., pp. 15.

Hartwig, E., (1994) “Observations regarding problems to commercialize non aluminum web coating.” Barkish, R. (ed.)/ Barkish Materials Corp.: Proc. 8th Intern. Conf. Vac. Web Coating; Las Vegas, Nevada, pp. 10.

Hoffmann, G. et al., (1994) "Transparent barrier coatings by reactive evaporation." Society of Vacuum Coaters, 37th Ann. Tech. Conf. Proc., pp. 155.

Irissin-Mangata, J., Bauduin, G., and Boutevin, B., (2000) Bilayer films composed of wheat gluten film and UV-cured coating: water vapor permeability and other functional properties. Polymer Bulletin, 44, 409-416.

Ichimura, K., and Kato, K., (2000) "Photo-Curing Technology Data Book" pp. 52 (in Japanese).

Ichinose, H., (2001a) Peroxotitanium type coating agents. Ceramics, 36, 586-587 (in Japanese).

Ichinose, H., Terasaki, M., and Katsuki, H., (2001b) Properties of peroxotitanium acid solution and peroxo-modified anatase sol derived from peroxotitanium hydrate. J. Sol-Gel Sci. Technol., 22, 33-40.

International Organization for Standardization, (2007) "Paints and varnishes -- Cross-cut test. ISO 2409.”

Japanese Industrial Standards Committee, (1999) "Testing methods for paints - Part 5: Mechanical property of film - Section 6: Adhesion test (Cross-cut test). JIS K 5600-5-6" (in Japanese).

Japanese Industrial Standards Committee, (2009) "Testing methods of pressure-sensitive adhesive tapes and sheets. JIS Z0237" (in Japanese).
Kelly, R.S.A., (1994) "Development of aluminum oxide clear barrier films." Society of Vacuum Coaters, 37th Ann. Tech. Conf. Proc., pp. 144.

Lippens, P. et al., (1998) "Sputter deposited titanium-oxide: a winning coating for many applications.” Barkish, R. (ed.): Proc. 12th Intern. Conf. Vac. Web Coating; Reno, Nevada, USA, October 21-23, 1998, pp. 370.

Lohwasser, W. et al., (1995) "Electron beam oxide coating on plastic films for packaging." Society of Vacuum Coaters, 38th Ann. Tech. Conf. Proc., pp. 40.

Matsuoka, M., and Anpo, S., (2006) The antimicrobe by the photocatalyst I., Bokin Bobai, 34, 439-449.

Ohta, S., (1977) "Degradation of the oil and fat food and the prevention." Saiwai Shobo, pp. 104 (in Japanese).

Ozaki, K., Kigure, H., and Iwasawa, N., (2001) Light-hardening resin composition and photo curing coating. Patent 2001-75281 (in Japanese).

Pascall, M.A., Harte, B.R., Giacin, J.R., and Gray, J.I., (1995) Decreasing lipid oxidation in soybean oil by a UV absorber in the packaging material. J. Food Sci., 60, 1116-1119.

Schiller, N. et al., (1998) "Oxide coating on plastic film.” Society of Vacuum Coaters, 41st Ann. Tech. Conf. Proc., pp. 370.

Schiller, N., Morgner, H., Fahland, M., Straach, S., Raebisch, M., and Charton, C., (1999) Transparent oxide coatings on plastic webs for emerging applications. Proc. Annu. Tech. Conf. Soc. Vac. Coaters, 42, 392-396.

Schiller, S. et al., (1996) "Web coating by reactive plasma activated evaporation and sputtering processes." Society of Vacuum Coaters, 39th Ann. Tech. Conf. Proc., pp. 371.

Schroder, M.J.A., Scott, K.J., Bland, K.J., and Bishop, D.R., (1985) Flavour and vitamin stability in pasteurized milk in polyethylenecoated cartons and in polyethylene bottles. J. Soc. Dairy Technol., 38, $48-52$.

Togeda, H. (2006) The antimicrobe by the photocatalyst II. Bokin Bobai, 34, 507-514.

Vassila E., Badeka, A., Condyli, E., Savvaidis, I., and Kontominas, M.G., (2002) Chemical and microbiological changes in fluid milk as affected by packaging conditions. Int. Dairy J., 12, 715-722.

Van Aardt, M., Duncan, S.E., Marcy, J.E., Long, T.E., and Hackey, C.R., (2001) Effectiveness of poly(ethylene terephthalate) and high- density polyethylene in protection of milk flavor, J. Dairy Sci., 84, 1341-1347.

Watanabe, T., Aoki, S., Ohta, S., Shirono, K., and Tanaka, A., (1997) Anti-bacterial film suitable for food packaging. Patent Int.

White, C.H., (1985) Consumer reaction to colored plastic milk jugs. J. Dairy Sci., 68, 261-264. 